\title{
Malaysian Hybridity: Issues of Kinship Practices and Identity Crisis
}

\author{
ALICIA LOH CHUI YINN \& NWANESI PETER KARUBI*
}

\author{
Faculty of Social Sciences and Humanity, Universiti Malaysia Sarawak, 94300 Kota Samarahan, Sarawak, \\ Malaysia \\ *Corresponding author: pknwanesi@unimas.my
}

\begin{abstract}
This article explores the issues of hybridity and its impacts and bearing to identity crisis in relation to kinship practices among the Euro-Asian families in Malaysia. To demonstrate the empirical and scientific nature of this study, qualitative methods were used whereby respondents were interviewed either face to face interview or through audio interviews. Furthermore, focus Group Discussion and empirical observation were fully utilized to obtain and analyzed for both quality and logical conclusion. Indeed, the data from the field demonstrate that the offspring of mixed marriages had either conscious identity crisis, unconscious or denied identity crisis or no identity crisis due to factors such as religion, socializing, education, and exposure by parents. Thus, the majority of the research respondents identified themselves based on "Others" but there are complexities to this when it comes to formal and informal identification.
\end{abstract}

Keywords: Family, hybridity, identity crisis, kinship, mixed-marriages

Copyright: This is an open access article distributed under the terms of the CC-BY-NC-SA (Creative Commons Attribution Non Commercial Share Alike 4.0 International License) which permits unrestricted use, distribution, and reproduction in any medium, for non-commercial purposes, provided the original work of the author(s) is properly cited.

\section{INTRODUCTION}

The idea of intermarriage is no doubt exogamous where one marries out of their own community to another of a completely different culture, customs, traditions and law. Different kinship systems, and kinship roles come with different cultures of different communities. Hence, when two individuals marry into different kinship systems, it may or may not clash with one another. Kinship according to Scheffler in Holy (1996), talks about how kinship and descent, describes one's egocentric system of social identity and status in their kinship system or descent system. Generally, in Malaysia, the notion of inter-kinship marriage is not frowned upon, nor, is it a social vice or issue. Malaysia (formerly known as, Tanah Malaya) as a country has been colonized by several countries. These include Portuguese, the Dutch, the Great Britain and Japanese; with the British colonization the longest, lasting up to a total of 120 years.

Returning to the idea of marriage between different kins, intermarriage has appealed to many young couples in Malaysia, hence an era of hybrid children. Regardless of this, the hybridity of kinship practices has not been widely studied in Asia. With only a handful theoretical studies done, and several others carried out in places like Australia, America and Jamaica. These studies were mostly consisting of studies on hybridity and kinship practices of the Chinese society, and intermarriage in the context of American kinship systems. Thus, the aim of this study is to explore the impact of hybridity in relation to identity crisis vis-à-vis kinship practices among EuroAsian families in Malaysia.

In the context of Malaysia, the idea of inter-kinship marriages is very common, and words such as Pan-Asian (Pacific-Asian / Asian Americans), Eurasians (European Asians), Kristang (Portuguese Malaysians) or even local terms such as Mamak (Indian-Malay), Chindians (Chinese-Indians), Baba Nyonya (Chinese-Malay) and so forth has been created solely to distinguish inter-kinship marriages and their offspring. Yet, despite having these specific labels from each ethnic group, there is constantly problems regarding official recognition of children of mixed-marriages. For example, government official documents usual provides ticking boxes for "ethnic identification" in forms for Malay, Chinese, Indians and Others. Unfortunately, most of times, children born of mixed marriages often have to tick this 'Others' box or the "ethnic" that they like depending on their mood of the day. Similar misrepresentation of identity is common in many American states. For example, Graham cited in Stewart and Goldfard (2007) criticized the U.S Census Bureau's "check on" racial and ethnic classifications to which she completely rejects saying that it is solely for "nice demography". Goldfard noted how this practise is discriminatory in nature when she argues, "it is a form of discrimination towards those who are born of parents of different race”. This writer's constructive argument and other similar debates on the ticking of 'one box', the 2000 
U.S Census hence permitted the ticking of multiple racial/ethnic classifications. Such practise is not echoed or debated here in Malaysia, as race is often sensitive topic. But that leaves the hybrid community in the state of limbo. In view of the above, it vital to explore the following research objectives. These include; to determine the extent of how hybridity impacts on an individual identity crisis, and to critically assess how people with EuroAsian identities identify themselves in Malaysia.

\section{MATERIALS \& METHODS}

The study utilized the qualitative method. Employing this method ensures data collection are in-depth and empirically gathered. Thus, providing an insightful information and details in relation to the issue on hybridity, kinship practices and identity crisis. The qualitative data gives a more in-depth insight on things as well as obtain information that can be prodded when asked. Indeed, utilisation of qualitative method inn this study, empower the researcher to obtain unspoken data but were understandable by the researcher during the interviews and group discussion. Thus, the research population were the offspring of the Euro-Asian parentage. These couples are in a marriage relationship or legal union. Such couple are Malaysians-Non-Malaysians such as Chinese MalaysianBritish, Portuguese Malaysian-Indian Malaysian and so forth. This population or target group are individuals above the age of 18 years old. This is because individuals under the age of 18 is thought to be less knowledgeable in relation to this study's research questions. Respondents were chosen from those residing in the Federal Territory of Kuala Lumpur as well as Selangor, Malaysia. As to why the research population is chosen from the Federal Territory of Kuala Lumpur, it is because Kuala Lumpur is by all standard the biggest city in Malaysia. It is both the socio-economic and political capital of Malaysia. The city is known to be one of the most diversified cities in the world. This is in terms of ethnic composition, religion and groups. It is considered a mega-city. Besides Kuala Lumpur has a high rate of immigrants from all over the world, and the rate of mixed-marriage is understandably very high. Research sampling for this study was based on purposive and snowball samplings. The scope of this study is to understand to the extent hybridity impacted on an individual's identity and how the individuals identify themselves in Malaysia. The study area is the Federal Territory of Kuala Lumpur as it is the capital city of Malaysia. As of 2017, the population of Kuala Lumpur stands at 1.79 million people (Department of Statistics Malaysia, Official Portal) with its Gross Domestic Product per capita at current prices of 2016 at RM101,420 (preliminary) hence it being a magnet to migrants from overseas. As mentioned earlier, the city's socioeconomical position has encouraged and continues to encourage the rising number of mixed-marriages in Malaysia.

\section{RESULTS}

\section{Discuss On Hybridity Versus Identity Crisis}

Amongst one of the most popular "hybrid" children, is Barrack Obama whereby he is a descendant of American of English and Irish descent and an African Heritage. If we look at it from the Asian context, it is nothing more than another person who would tick the "Others" box, but in America, Obama being a hybrid child is great debate not on the basis on how he calls himself "Black" (because hybrid children who have "Black" heritage are required to tick "Black") but on the basis that why does he call himself "Black".

Back in those days, hybridity or intermarriage for that matter, was a criminal act that would subject a person (two persons, but usually only the darker skinned person) to be whipped, punished, jailed, fined and sometimes even killed as was explained earlier in the previous chapter. Up till the 1850, multiracial marriage was unexpected, but no one could stop people from having interracial marriages, hence the presence of a terminology for those who have married interracially. It wasn't until the year 1967, where it became a law abolishing the punishment and fines of those of intermarriage under the decision called the Loving Decision that people started to change. During the years after 1967, interracial marriage registry took a leap of numbers up to a total rise of $88 \%$ of the marriages registered (see Bond, 2001).

In Britain on the other hand, intermarriage was a rather widely accepted notion due to the dynamics of colonialism. British men who had both temporary moved or migrated out for jobs, work, research as well as war had married with the local people. Race relations hence emerged due to the status of marrying a person of a different race and it has been noted then rather a number of men had relationships with women of different colour outside of the country (Henriques as cited in Katz, 1996). Hence, when some of these women are brought back to Britain with them they will face, what Weedon (2004) says to be part of diasporic communities 'whom have different projections of identities based on both traditional culture of their origin and modern culture of that from the new cultural engagement one has with their new place of migration'. Ang (2003) argued, the intermarriage among the white and black, periphery and core, cultural power relations are in place of this, due to the hierarchical dualisms whereby she believes at times, those in power might have married interracially only to be seen as a prize. 
Hence, if we compare the work of Stewart and Goldfarb in 2007, they argued that 'race' and 'ethnicity' is something that is connected and intertwined meaning that while there might be a biological basis to racial categories, it doesn't really have anything biological in much sense other than skin colour. Hence, the notion of self-identification for one's self. According to Huntington (2004), an individual's identity is concerned through four points namely; identity is the form of grouping, identity which is constructed, identity which is multiple as well as identity as a product of continuous interaction. Identities according to Hall (1996) are something constituted internally in the form of historical resources, language and culture only to make it represent ourselves not to others but to our own selves. Gecas (1982), paraphrasing Bem's "self-perception theory" on an individual's behaviour, maintains that people's behaviour could be affected from observing and making our reasoning for certain behaviours which in turns affect how an individual identifies their own behaviour. The above understanding differ from Berger and Luckmann (1966) depiction of identity. They argued that identity is something that is created from within us in terms of realities that we create inside us as an effect of the things that happen around us. Some of the argument of Luckmann are depicted in the succeeding conceptual framework.

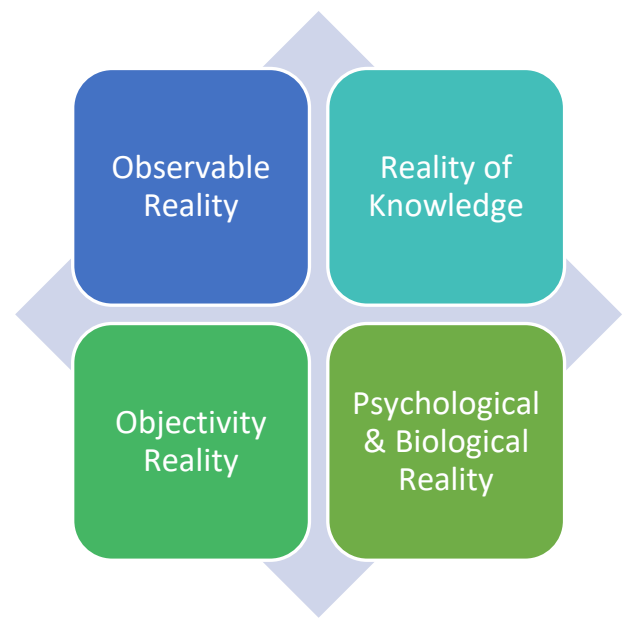

Figure 1. Conceptual framework of background of identity is based on the work of Berger and Luckmann (1966).

\section{DISCUSSION}

\section{Extend Of How Hybridity Impacts On An Individual's Identity Crisis (Cultural Dominance)}

The key informant were asked which of their culture is dominant, the respondents ML and $\mathrm{MF}^{1}$ expressed that they are more inclined to their Chinese side then they are of their English side despite saying that they celebrated both sides cultural festivities and heritance equally. MF says that they celebrate Christmas just as grand as Chinese New Year because it gives their mother a memory of something and to not lose that side of her culture since she is so far away from her natal family.

In terms of dominant religious culture whereby $\mathrm{J}$ and $\mathrm{G}$ are more inclined towards their religious culture namely Christianity. J says "I think I am equally familiar" with both sides of his Portuguese Eurasian side but then proceeds to focus on his Christian side saying that he celebrates Church celebrations such as Christmas, Easter, Good Friday and Lent. G, on the other hand, informs that since he grew up with his maternal grandparents during his primary years and his paternal side of the family during the latter part of his life, he is more inclined to his Indian side than his Portuguese side. G lives closer to his paternal family/ Indian family's side and has more interaction to those cousins shows a closer distance to those cousins as compared to his maternal family/ Portuguese side cousins. This shows that environment pushed him to be more inclined to his Indian side than Portuguese because he was more exposed to that side of the culture so in that way can we believe that $\mathrm{G}$ more Indian dominant or so, Wodak de Cilia, Reisigl and Liebhart (1999) had said about 'social identity' namely how

\footnotetext{
${ }^{1}$ The abbreviation letters ML, MF, B, JS, JV, G and K are alphabets relating to the respondent's name. This is to keep information related to the respondents confidential.
} 
it reflects on individuals who are given 'social characteristics and role expectations from other people' develop their sense of identity based on eternal attributes given by others.

However, there is no dominant culture at all for respondent $\mathrm{K}$ who is a Malay-German hence by default in Malaysia, any non-Muslim who marries a Muslim has to convert to Islam and hence Islam being the dominant culture of the person. But for $\mathrm{K}$ this is not the case because $\mathrm{K}$ celebrates both sides of her Malay and German side.

\section{Perception Of Themselves As Being Half-Half}

Let's start with conscious/sub-conscious identity crisis namely of respondents ML and MF. When both respondents were asked during the focus group discussion, it occurred that they did not realize they were facing identity crisis. In MF words, she says:

"Cause we lose a lot of our English culture, English they don't have many traditions or celebrations, not like, not like here. So the culture is not as strong, not as dominant, so when it is Christmas we make sure to do it quite elaborate, make sure we always have dinner, always have a celebration cause so that we don't lose it. Because Chinese culture is so strong that we have been living here for our whole life, technically it is still part of us and also like for my mom, a lot of the time, so I think that's why we emphases to celebrate that as well whereas the Chinese side is an automatic thing that we will have to definitely do it. Like the English side is like an extra effort that we want to so that we don't lose that side of us. If not, we are very one sided already."

Secondly comes the denied identity crisis where $\mathrm{J}$ says that he does not have identity crisis because he feels no difference and has no feelings towards it. $\mathrm{G}$ and $\mathrm{K}$ also said that they do not have an identity crisis but $\mathrm{G}$ noted that he seems to have an identity crisis solely because he thinks he is Indian based on his skin colour and what formal papers (e.g. birth certificate, identification card) has to say about him rather than what he has to say about himself that is an Indian-Portuguese.

\section{Opinions On External Perceptions Of Their Identity}

First and foremost, it is noted that all respondents have experienced being asked by people (strangers, extended families, peers, friends, colleagues, and the public) the question of "What are you?" or "Are you mixed?" or "Celup $k e^{2}$ ?" or even the occasional "Are you (ethnic category)?" An example of conversation provided by K would be:

“They would ask me 'Are you Malaysian?' I would say yes. Then they'll say 'What are you?' then I would say 'I'm Malay' and then they'll look at me and go 'Are you mixed?' then I will answer yes."

And secondly, a majority of respondents have been mistaken for a different ethnic classification. Mistaken ethnic classification here means that people have mistaken them for a different ethnic group. Those who expressed positive responses to this were J who said that he didn't mind what people thought of him but at times finds it funny at how people can come up with such a judgement (on J being a different ethnic). Those who expressed that they were at neutral standing were for example B, who said that his opinion on this depends on whether the person has met a Eurasian before or not. Among those who expressed negative responses were ML and MF who said that because of other people's perception on them during childhood, they were often labelled as people who were cocky and arrogant solely on the way they look (Both ML and MF looks more Caucasian then Chinese). In regards to mistaken identities, some of them express to be insulted for being mistaken such as JV (refer previous paragraph) and B. B says that he was very offended when people mistake him for a Malay especially during fasting month because he wasn't given food:

'There are times where I wasn't allowed to eat because they thought I was a Malay and I had to clarify that no, I'm not. I always have to go a Chinese shop instead because no one judges you there. (s.p.)"

Hence, the above sub-section can go hand in hand with what has been said by Gordon as cited in Gecas (1982) hence talks about how there is a distinction between identity is formed based on situation.

\footnotetext{
${ }^{2}$ Celup ke is the informal Malay sentence for 'Are you mixed?'
} 


\section{Identification In Malaysia And The 'Others' Box}

Among all respondents, 5 respondents would put 'Others' while another 2 will put a specific ethnic category should they fill in a form and among these two are $\mathrm{K}$ who is Malay and $\mathrm{G}$ who is Indian. Such complexities arise when respondents talked about the measure of importance when filling in forms as well as their habit of choosing whether to explain or not explain who they are and what their backgrounds are or otherwise the importance of people during the conversation.

Next we look at respondents' habit of choosing whether to explain who they are and their backgrounds are or not or otherwise the importance of people during conversations. B says that he would introduce himself as a 'Eurasian' and only upon being asked does he say that he is a mix of Portuguese, Chinese and Indian mix. The level of importance here for him is differentiated on whether he would say that he is Portuguese Chinese or otherwise. B explains that he would tell people that he speaks Portuguese with his family at home and he celebrates Chinese celebrations. Respondent $\mathbf{J}$ is in a similar situation where he identifies himself as a Portuguese Eurasian solely because his parents are both Portuguese Eurasians. J says that his family (parents and grandparents) are born locally but didn't know how far back his genealogy has settled in Malaysia. G, says that he identifies himself as an Indian unless people asks him specifically questions like "What are you? What's your mom? What's your dad?" because of the colour of his skin to which G says when people look at him they automatically think of him as an Indian and if he is lazy, then he will not correct them.

\section{Opinions On The 'Others' Box}

Among those who mentioned that 'Others' is a fair and neutral term is that of MF and ML who says that they believe it means 'Other than the race stated and not others in that sense'. To them, 'others' does not sound offensive solely because (as ML says) the forms can't simply list down all the ethnic groups in Malaysia seeing as Malaysia is a multicultural country. An example that they gave that was also in the 'Others' box were Chindians (Chinese-Indians) which is an ethnic combination of the two major ethnic groups in Malaysia.

Those who took a slightly negative view on 'Others' were such as B who said "As I get older, I feel it is weird la but now if I see it's others then its other la because I can't specify between Malay, Chinese or Indian. (s.p.)” B backs up his statement by saying that the number of Eurasians in Malaysia may be a small number but it is increasing and hence his change of thoughts on the notion of 'Others'. JV had a rather neutral opinion on 'Others' before turning into a more negative opinion on it. Why this is so, because JV says that she didn't have any opinion on it except that it would be good if they had Eurasian option since Malaysia doesn't only have three races. G, expressed his displeasure of the notion of 'Others' saying that "Why Others?" and saying that Malaysia is a multiracial country so he doesn't understand this segregation and if he could, he would put 'Others' into the 'Others' box to prove his point. "Why is there no Malaysian? This segregation is irrelevant. In America there is no White, no Black, there are just American. They don't ask stuff like that. So why can't Malaysia be Malaysian? The people seeing the forms wouldn't know if I really am 'Others' or not." To which G says that "I don't want to see myself as an Indian or whatever, I want to be Malaysian.”

The aim of this study was to explore how hybridity affects/cause identity crisis as an issue of kinship practices among Euro-Asian families in Malaysia. To arrive at a logical conclusion in this study, relevant literatures were thoroughly discussed thus, the major findings will be discussed and concluded in this chapter.

\section{CONCLUSION}

"Role-identity" as stated by Gecas (1982) states that it is a link of self-conceptions of an individual to the social structures around the individual because roles are assigned to these individuals when they are part of the social structure in terms of organization elements. Identity crisis among my respondents gives root to when Huntington (2004) gave an example of the female psychologist in a male dominated field would most probably think herself as a woman while a female psychologist in a female dominated field would most probably think herself as a psychologist because while she has both the identity of a woman and as a psychology she chose to identify herself differently based on how different others are to her.

\section{REFERENCES}

Ang, I. (2003). Together-in-difference: Beyond diaspora, into hybridity. Asian Studies Review, 27(2), 141-154.

Bond, B. G. (2001). Interracial families. In The Family in America: An Encyclopaedia (Vol. 2, pp. 576-596). United States of America: ABC-CLIO Inc.

Gecas, V. (1982). The Self-Concept. Annual Review of Sociology, 8,1-33.

Hall, S. (1996). Introduction: Who needs ‘identity’? In S. Hall and P. D. Gay (Eds.) Questions of Cultural Identity (pp. 1-17). London: SAGE Publications Ltd. 
Holy, L. (1996). Anthropology, Culture \& Society: Anthropological Perspectives on Kinship. Chicago, IL: Pluto Press.

Huntington, S. P. (2004). Who are we? The challenges to America's national identity. United States of America: Simon \& Schuster.

Katz, I. (1996). The construction of racial identity in children of mixed parentage: Mixed metaphors. London and Bristol, Pennsylvania: Jessica Kingsley Publishers.

Stewart, P., \& Goldfarb, K. P. (2007). Historical trends in the study of diverse families. In Bahira Sherif Trask \& Raeann R. Hamon (Eds.). Cultural Diversity and Families: Expanding Perspectives. United States of America: Sage Publications, Inc.

Weedon, C. (2004). Identity and Culture: Narratives of Difference and Belonging. England: Open University Press.

Wodak, R., Cilia, R. D., Reisigl, M., \& Liebhart, K. (1999). The Discursive Construction of National Identity (A. Hirsh \& R. Mitten, Trans. Edinburgh: Edinburgh University Press (Original work published 1998). 